\title{
Tape Augmentation Does Not Affect Mid-Term Outcomes of Medial Patellofemoral Ligament Reconstruction in Skeletally Mature Adolescent Patients
}

\author{
Taylor E. Hobson, M.D., M.B.A., Kelly M. Tomasevich, B.A., Noah J. Quinlan, M.D., \\ Alexander J. Mortensen, M.D., and Stephen K. Aoki, M.D.
}

\begin{abstract}
Purpose: To evaluate mid-term outcomes after medial patellofemoral ligament (MPFL) reconstruction with and without tape augmentation in the skeletally mature adolescent population. Methods: All patients under age 18 with recurrent patellar instability treated with surgery at a single institution by a single surgeon from January 2013 through June 2017 were identified by current procedural terminology codes. Inclusion criteria were (1) primary MPFL reconstruction, (2) minimum 3 years' follow-up, (3) skeletal maturity. Exclusion criteria were (1) bilateral MPFL reconstruction using different techniques on each knee, (2) prior surgery for patellar instability. Chart and imaging review was completed. Patients were contacted to complete a questionnaire, which included the International Knee Documentation Committee (IKDC) form. Results: Fifty-one of 92 eligible patients completed questionnaires. Two patients were excluded. Twenty patients underwent 23 non-augmented MPFL reconstructions; 29 patients underwent 33 augmented MPFL reconstructions. Group demographics were similar. At $4.9 \pm 1.2$ years follow-up, mean IKDC scores were 77.4 and 79.4 in the nonaugmentation and augmentation groups, respectively. Significantly fewer patients in the augmentation group experienced further injury to their ipsilateral knee compared to the non-augmentation group $(6 \%$ vs $30 \%, P=.019)$. Fewer knees in the augmentation group developed recurrent subjective instability or dislocation after initial surgery requiring surgical correction compared to knees in the nonaugmentation group, although this difference was not significant $(6 \%$ vs $17 \%, P=0.181)$. Overall patient-reported outcomes were similar between the 2 groups. Conclusions: There were no significant differences in patient-reported outcomes after MPFL reconstruction with or without tape augmentation. Tape augmentation significantly decreased the risk of subsequent ipsilateral knee injuries, although it did not show a significant difference in recurrent dislocations. Level of Evidence: IV, therapeutic case series.
\end{abstract}

A cute patellar dislocations account for $2 \%$ to $3 \%$ of all knee injuries. ${ }^{1}$ In children younger than age

From the University of Utah, Department of Orthopaedic Surgery, Salt Lake City, Utah, U.S.A.

The authors report the following potential conflicts of interest or sources of funding: T.E.H. reports personal fees from Stryker Corporation and Medical Device Business Services Inc. N.J.Q. reports personal fees from Stryker Corporation and Medical Device Business Services Inc. S.K.A. reports personal fees from Stryker Corporation, Active Medical, and Smith $\theta$ Nephew. Full ICMJE author disclosure forms are available for this article online, as supplementary material.

Received March 23, 2021; accepted October 11, 2021.

Address correspondence to Stephen K. Aoki, M.D., Department of Orthopaedic Surgery, University of Utah, 590 Wakara Way, Salt Lake City, UT 84108.E-mail: stephen.aoki@hsc.utah.edu

(C) 2021 THE AUTHORS. Published by Elsevier Inc. on behalf of the Arthroscopy Association of North America. This is an open access article under the CC BY-NC-ND license (http://creativecommons.org/licenses/by-nc-nd/4.0/). 2666-061X/21421

https://doi.org/10.1016/j.asmr.2021.10.011
16, the incidence of patellar dislocation is 43 per $100,000 .^{2-5}$ Recurrence of patellar dislocation has been reported to occur in $44 \%$ to $71 \%$ of first time dislocators who do not undergo surgery. ${ }^{6-10}$ Similarly, an estimated $15 \%$ to $44 \%$ of patients with first-time patellar dislocations subsequently develop recurrent patellar instability. ${ }^{5,11-16}$ Although patellar instability may manifest as recurrent patellar dislocations, adolescents and adults may also present without dislocation, as a sense of discomfort, unease, or "something being out of place" in the knee. ${ }^{17}$

The cause of patellar instability is multifactorial. Several anatomic factors including hypermobility, patella alta, increased tibial tubercle-trochlear groove distance, patellar tilt, rotational deformity, and trochlear dysplasia are prevalent in patients with a history of patellar dislocation or instability. ${ }^{14,18-22}$ There also appears to be a genetic component, with approximately $28 \%$ of patients reporting a family member with 
a history of similar symptoms. ${ }^{23}$ Patients with recurrent patellar instability have poor outcomes in the absence of surgical intervention. Functional limitations may include pain, mechanical symptoms, or activity restriction, including inability to participate in sport. ${ }^{2,5,14}$ Long term, patients may worsen chondral damage affecting the patellofemoral joint. ${ }^{13,24}$

The medial patellofemoral ligament (MPFL) is the primary ligamentous stabilizer that prevents lateral patellar dislocation. MPFL reconstruction for recurrent patellar instability has become a mainstay of operative management for patellar instability. However, with any operative intervention for patellar instability, failure rates have been reported from $5 \%$ to $30 \%$, broadly because of technical failure, unaddressed static and dynamic pathoanatomy, or intrinsic risk factors such as collagen disorders or ligamentous laxity. ${ }^{25}$ More recently, MPFL reconstruction has been performed using suture augmentation to strengthen the graft and prevent against graft failure. ${ }^{26}$ However, the use of synthetic materials has the potential to overconstrain the patellofemoral joint, resulting in prolonged rehabilitation time, anterior knee pain, and degenerative changes of the patellofemoral joint. ${ }^{27}$

The purpose of this study is to evaluate mid-term outcomes after MPFL reconstruction with and without tape augmentation in the skeletally mature adolescent population. We hypothesized that patients in both groups would have improved outcomes, but those who underwent tape augmentation would have fewer ipsilateral re-injuries and surgeries.

\section{Methods}

\section{Cohort Selection}

A retrospective cohort review was performed with approval from the institutional review board. All patients under age 18 who underwent MPFL reconstruction by the senior author (S.K.A.) from January 2013 through June 2017 were identified by current procedural terminology codes. Inclusion criteria were (1) primary MPFL reconstruction, (2) minimum 3 years' follow-up, and (3) skeletal maturity. Exclusion criteria were (1) bilateral MPFL reconstruction using different techniques on each knee and (2) prior surgery for patellar instability. All patients underwent a trial of nonoperative management before undergoing surgery. Nonoperative management included activity modification and physical therapy, followed by a gradual progression of activities. Surgery was considered in patients who experienced persistent instability and were unable to return to their desired level of function.

Operative and clinic notes were reviewed to verify index procedure. When available, radiographs were reviewed by 2 fourth-year orthopaedic surgery residents and a medical student (T.E.H., N.J.Q., K.M.T.) for trochlear dysplasia, trochlear Dejour classification, Insall-Salvati ratio, and Caton-Deschamps index.

\section{Surgical Technique and Postoperative Protocol}

All patients included in the study underwent MPFL reconstruction with the use of allografts. Patients were placed supine, and general anesthesia was utilized for all procedures. After administration of prophylactic antibiotics, a diagnostic knee arthroscopy was performed to evaluate the chondral surfaces of the patellofemoral joint, remove any loose bodies, and inspect the remainder of the knee for any concomitant pathology that was addressed accordingly. After this, attention was then directed to the open portion of the procedure. Incisions were made over the medial patella and medial epicondyle. Dissection was carried down to the level just above the capsule, where we then tunneled between the two incisions. After exposing the medial patellar surface, a guide pin was placed under fluoroscopic guidance at the junction between the superior third and inferior two thirds of the patella. Once positioning was confirmed, the patellar tunnel was drilled using a $5 \mathrm{~mm}$ reamer. The graft, with or without tape augmentation, was trimmed to fit $5 \mathrm{~mm}$ tunnels and then fixed into the tunnel using a $4.75 \mathrm{~mm}$ PEEK tenodesis interference screw (Arthrex, Naples, FL). When tape augmentation was used, suture tape was whipstitched to the allograft.

Attention was then directed to the femur. A perfect lateral of the knee was obtained using fluoroscopy. A guide pin was then placed slightly proximal and posterior to the medial epicondyle, correlating with Schottle's point on fluoroscopy. ${ }^{28}$ After confirming isometry using the sutures attached to the patellar side, a $5 \mathrm{~mm}$ reamer was used on the femoral side, and the graft was fixed with the knee flexed. The flexion angle during fixation was adjusted according to the dynamic exam and findings during isometry testing. The angle chosen for fixation correlated to the position where the graft was the longest, in order to avoid over tensioning. Isometry was checked once again to assure that the graft construct was either isometric or loosened in flexion to confirm that the graft was not over tensioned. Knee range of motion was checked to ensure the patient could achieve full flexion and extension. Wounds were thoroughly irrigated and closed in a layered fashion and patients were placed in a knee immobilizer. Patients were able to bear weight as tolerated using crutches with the knee in full extension beginning the day after surgery. Range of motion was also allowed from $0^{\circ}$ to $90^{\circ}$ while not weightbearing beginning the day after surgery, with gradual progression as tolerated beginning after the first week.

\section{Survey Methodology}

Patient contact information including mailing address, phone number, and e-mail were obtained through review of electronic medical records. Patients 
were first contacted by mail alerting them of the study. Patients were then contacted at least 5 times by phone and by e-mail between March 11, 2020, and September 30,2020 , to maximize response rates. Those willing to participate were asked to complete a questionnaire using the Research Electronic Data Capture (REDCap, Vanderbilt University, Nashville, TN) online service. Questionnaires were completed over the phone with the researcher inputting responses directly, or patients were sent an email link to the REDCap survey for completion at a later time. Patients who requested to complete the survey by email were sent automated emails weekly for 5 weeks or until questionnaire completion.

The REDCap questionnaire included the International Knee Documentation Committee (IKDC) form, ${ }^{29-32}$ the Marx Activity Scale, ${ }^{33}$ and questions pertaining to knee pain and function, satisfaction with surgery, and additional injury or surgery on either knee (Appendix 1). Chart review was performed to collect demographic and surgery information and to confirm patient-reported additional injuries and surgeries on both knees. Patients were directed to respond to the survey using their worse knee as a reference point.

\section{Statistical Analysis}

Survey data was exported to Microsoft Excel. Data was analyzed using Microsoft Excel and SPSS version
26. All variables were assessed for normality using the Shapiro-Wilk test. Unpaired $t$-tests were used for normally distributed data and Mann-Whitney U tests were used for non-normally distributed data. Categorical variables were assessed using Pearson $\chi^{2}$ and Fisher's exact tests. Significance was set at a $P$ value $<.05$.

\section{Results}

Eighty-two patients underwent 92 MPFL reconstructions between January 2013 and June 2017. Fifty-one patients $(61 \%)$ who underwent 59 MPFL reconstructions responded to the survey questionnaire. One patient was excluded because of prior rotational osteotomy for patellar instability, and 1 patient was excluded for bilateral surgery using different techniques on each knee. Among the 49 included patients, 20 patients underwent 23 MPFL reconstructions in the non-tape augmentation group, whereas 29 patients underwent 33 MPFL reconstructions in the tape augmentation group.

Demographics of the 2 groups were similar (Table 1 ). Mean age, sex distribution, and body mass index were similar at 15.3 years (R: 12.4-17.8), 61\% female, and $24.8 \mathrm{~kg} / \mathrm{m}^{2}$ (R: 16.1, 38.4) versus 15.4 years (R: 12.618.2 ), $70 \%$ female, and $24.8 \mathrm{~kg} / \mathrm{m}^{2}$ (R: 18.1, 37.7) in the nonaugmentation and augmentation groups, respectively. Insall-Salvati ratio, Caton-Deschamps index, and trochlear Dejour classification did not differ

Table 1. Patient Demographics

\begin{tabular}{|c|c|c|c|}
\hline & Nonaugmentation $(\mathrm{n}=23)$ & Augmentation $(\mathrm{n}=33)$ & $P$ value \\
\hline Mean (SD) & $15.3(1.6)$ & $15.4(1.6)$ & \\
\hline Range & $12.4,17.8$ & $12.6,18.2$ & \\
\hline Female & $14(61 \%)$ & $23(70 \%)$ & .492 \\
\hline Male & $9(39 \%)$ & $10(30 \%)$ & \\
\hline Operative knee & & & .299 \\
\hline $\mathrm{BMI}, \mathrm{kg} / \mathrm{m}^{2}$ & & & .298 \\
\hline Mean SD & $23.7(5.3)$ & $24.8(4.8)$ & \\
\hline Range & $16.1,38.4$ & $18.1,37.7$ & \\
\hline Insall Salvati ratio, ${ }^{*}$ mean (SD) & $1.3(0.3)$ & $1.4(0.3)$ & .735 \\
\hline Caton Deschamps index, ${ }^{*}$ mean (SD) & $1.3(0.2)$ & $1.3(0.2)$ & .981 \\
\hline \multicolumn{4}{|l|}{ Trochlear dysplasia*, n (\%) } \\
\hline $\mathrm{B}$ & $0(0 \%)$ & $1(3 \%)$ & \\
\hline $\mathrm{C}$ & $1(4 \%)$ & $0(0 \%)$ & \\
\hline $\mathrm{D}$ & $0(0 \%)$ & $00(\%)$ & \\
\hline Preoperative IKDC ${ }^{\dagger}$ & & & .718 \\
\hline Mean (SD) & $46.8(16.8)$ & $40.3(18.1)$ & \\
\hline Range & $33.3,70.1$ & $6.9,69.0$ & \\
\hline
\end{tabular}

*Lateral films were unavailable in 3 knees $(13 \%)$ in the nonaugmentation group and 1 knee $(3 \%)$ in the augmentation group. Sunrise view radiographs were unavailable in 11 knees $(48 \%)$ in the nonaugmentation group and 4 knees $(12 \%)$ in the augmentation group.

${ }^{\dagger}$ Preoperative IKDC scores were available in 4 knees $(17 \%)$ in the nonaugmentation group and 23 knees $(70 \%)$ in the augmentation group. 
significantly between the 2 groups. Lateral films were unavailable in 3 knees $(13 \%)$ in the nonaugmentation group and 1 knee $(3 \%)$ in the augmentation group. Sunrise view radiographs were unavailable in 11 knees $(48 \%)$ in the nonaugmentation group and 4 knees $(12 \%)$ in the augmentation group.

Surgical data are described in Table 2. The augmentation group underwent more procedures than the nonaugmentation group at the time of surgery $(58 \%$ vs $22 \%, P=.008)$, with 15 of 19 patients $(45 \%)$ in the augmentation group undergoing loose body removal.

Patient reported outcomes are detailed in Table 3. The augmentation group had shorter follow-up at a mean of 4.1 years ( $R$ : $3.0-5.2$ ) versus 6.0 years ( $R$ : $4.2-7.0$ ) in the nonaugmentation group $(P<.001)$. Outcomes did not differ significantly between the two groups. Mean IKDC scores were 79.4 and 77.4 in the augmentation and non-augmentation groups, which exceeded the patient acceptable symptom state (PASS) previously defined as 75.9. ${ }^{34,35}$ Mean Marx activity scale scores were 8.6 and 9.2, respectively. The augmentation group reported their operative knee as $82.4 \%$ (R: 40-100) of "normal," whereas the nonaugmentation group reported their operative knee as $80.9 \%$ (R: 17-100) of "normal."

Pain ratings did not differ significantly between the two groups. Regarding pain on a visual analog scale (VAS), the percentages of patients reporting pain less than a 3 at rest, with daily activity, and with sport were $86 \%$ vs $85 \%(p=1.000), 72 \%$ vs. $70 \%(p=0.915)$, and $45 \%$ vs $55 \%(p=0.484)$ in the augmentation and non-augmentation groups, respectively.

Satisfaction with surgery as rated on a Likert scale did not differ between the 2 groups $(P=.305)$. Overall patient satisfaction was high in both groups. Ten patients $(50 \%)$ reported being "very satisfied" in the nonaugmentation group, compared with 19 patients $(66 \%)$ in the augmentation group. When asked whether they would pursue MPFL surgery again, 18 patients $(90 \%)$ in the nonaugmentation group responded "definitely yes," compared with 23 patients $(79 \%)$ in the augmentation group.

Patients who underwent MPFL reconstruction participate in sport at similar levels as prior to surgery, regardless of technique used $(31 \%$ augmentation vs $20 \%$ nonaugmentation, $P=.516$ ). Patients in the augmentation group avoid sport more than their counterparts who did not undergo augmentation $(41 \%$ vs $30 \%$ ), although this difference was not significant $(P=.417)$. Of patients who refrained from sport, $75 \%$ in the augmentation group versus $83 \%$ in the nonaugmentation group reported doing so due to their knee $(P=.646)$.

Ten patients $(50 \%)$ in the augmentation group reported stiffness or loss of motion in their knee, versus 12 patients $(41 \%)$ in the nonaugmentation group $(P=$ $.551)$. Of patients who reported stiffness or loss of motion, $75 \%$ of those in the augmentation group and $40 \%$ of those in the non-augmentation group reported limitation of activity due to these symptoms $(P=.192)$. Eight patients $(28 \%)$ in the augmentation group reported instability occurring weekly or more, compared with 6 patients $(26 \%)$ in the nonaugmentation group $(P=.495)$.

Patients in the augmentation group sustained fewer ipsilateral knee injuries than the non-augmentation group ( $6 \%$ vs $30 \%, P=.019)$. Time between initial surgery and subsequent ipsilateral injury was $2.5 \pm 2.1$ years in the nonaugmentation group, whereas only 1 patient in the augmentation group sustained an ipsilateral injury 2.0 years after surgery. Overall, 2 knees $(6 \%)$ in the augmentation group developed recurrent subjective instability or dislocation after initial surgery requiring surgical correction, compared to 4 knees $(17 \%)$ knees in the nonaugmentation group $(P=.181)$. In the augmentation group, these injuries included

Table 2. Surgical Data

\begin{tabular}{|c|c|c|c|}
\hline & Nonaugmentation $(n=23)$ & Augmentation $(\mathrm{n}=33)$ & $P$ Value \\
\hline Procedure performed & & & $.008^{*}$ \\
\hline Isolated MPFL reconstruction & $18(78 \%)$ & $14(32 \%)$ & \\
\hline Chondral debridement & $2(9 \%)$ & $3(9 \%)$ & \\
\hline Partial medial meniscectomy & $0(0 \%)$ & $1(3 \%)$ & \\
\hline Partial lateral meniscectomy & $0(0 \%)$ & $1(3 \%)$ & \\
\hline Lateral meniscus repair & $0(0 \%)$ & $1(3 \%)$ & \\
\hline ACL reconstruction & $0(0 \%)$ & $1(3 \%)$ & \\
\hline Loose body removal & $3(12 \%)$ & $15(45 \%)$ & \\
\hline Graft & & & $<.001^{*}$ \\
\hline Gracilis allograft & $2(9 \%)$ & $21(63 \%)$ & \\
\hline Peroneus longus allograft & $14 \%)$ & $0(0 \%)$ & \\
\hline Semitendinosis allograft & $19(82 \%)$ & $12(36 \%)$ & \\
\hline Tibialis anterior allograft & $1(3 \%)$ & $0(0 \%)$ & \\
\hline
\end{tabular}

*Significant at the .05 level. 
Table 3. Patient-Reported Outcomes

\begin{tabular}{|c|c|c|c|}
\hline & Nonaugmentation $(\mathrm{n}=20)$ & Augmentation $(\mathrm{n}=29)$ & $P$ value \\
\hline Follow-up length, years & & & $<.001^{*}$ \\
\hline Mean (SD) & $6.0(0.6)$ & $4.1(0.7)$ & \\
\hline Range & $4.2-7.0$ & $3.0-5.2$ & \\
\hline Mean (SD) & $77.4(22.4)$ & $79.4(17.1)$ & \\
\hline Range & 20.7-100 & $34.5-100$ & \\
\hline Marx activity scale score & & & .654 \\
\hline Knee rated as a percentage of normal & & & .878 \\
\hline Mean (SD) & $80.9(20.4)$ & $82.4(17.3)$ & \\
\hline Range & 17-100 & $40-100$ & \\
\hline \multicolumn{4}{|l|}{ Pain on a visual analog scale $<3$} \\
\hline At rest & $3(15 \%)$ & $4(14 \%)$ & 1.000 \\
\hline With activities of daily living & $6(30 \%)$ & $8(28 \%)$ & .915 \\
\hline Neutral & $4(20 \%)$ & $2(7 \%)$ & \\
\hline Unsatisfied & $1(5 \%)$ & $0(0 \%)$ & \\
\hline Very unsatisfied & $0(0 \%)$ & $0(0 \%)$ & \\
\hline Undergo same care if needed & & & .126 \\
\hline Definitely yes & $18(90 \%)$ & $23(79 \%)$ & \\
\hline Probably yes & $0(0 \%)$ & $5(17 \%)$ & \\
\hline Neutral & $1(5 \%)$ & $0(0 \%)$ & \\
\hline Probably no & $1(5 \%)$ & $0(0 \%)$ & \\
\hline Definitely no & $0(0 \%)$ & $1(3 \%)$ & \\
\hline Play sports & $4(20 \%)$ & $9(31 \%)$ & .516 \\
\hline Avoid sports & $6(30 \%)$ & $12(41 \%)$ & .417 \\
\hline Due to knee & $5(25 \%)$ & $9(31 \%)$ & .646 \\
\hline
\end{tabular}

*Significant to the 0.05 level.

${ }^{\dagger}$ Confirmed via chart review.

nonspecific knee injury $(\mathrm{n}=\mathrm{l})$ and instability event $(\mathrm{n}=\mathrm{l})$. For the nonaugmentation group, injuries included ACL rupture $(\mathrm{n}=1)$, patellar dislocation $(\mathrm{n}=$ $1)$, instability event $(n=4)$, and nonspecific knee injury $(\mathrm{n}=1)$. Five knees $(22 \%)$ within the nonaugmentation group underwent further surgery on the ipsilateral knee, compared with 2 knees $(6 \%)$ in the augmentation group $(P=0.081)$. Time between initial and subsequent ipsilateral surgery was $2.2 \pm 1.5$ years in the nonaugmentation group and $2.3 \pm 1.6$ years in the augmentation group $(P=0.938)$. In the augmentation group, subsequent surgeries included revision MPFL reconstruction and tibial tubercle osteotomy $(\mathrm{n}=$ 2 ). In the nonaugmentation group, these surgeries included ACL reconstruction and lateral meniscus root repair $(\mathrm{n}=1)$, isolated revision MPFL reconstruction $(\mathrm{n}=1)$, revision MPFL reconstruction and lateral femoral condyle microfracture $(\mathrm{n}=1)$, revision MPFL reconstruction and tibial tubercle osteotomy $(\mathrm{n}=1)$, and revision MPFL reconstruction with distal femoral lateral opening wedge osteotomy, which was followed by a second revision MPFL reconstruction and hardware removal $(\mathrm{n}=1)$.

\section{Discussion}

In this series, adolescent patients undergoing MPFL reconstruction with and without tape augmentation for patellar instability at a mean of $4.9 \pm 1.2$ years followup had similar patient-reported outcomes. However, fewer patients in the tape augmentation group experienced further injury of their ipsilateral knee. Patients in both groups reported similar levels of recurrent patellar instability, including dislocation.

Patient-reported outcomes, including IKDC score, reported knee percent of normal, and VAS pain scores, did not differ significantly between the augmentation 
and non-augmentation groups. Xie et al similarly evaluated the clinical outcome of MPFL reconstruction for patellar instability using semitendinosis tendons with and without polyester suture augmentation, but found significant differences in IKDC score between the augmentation and non-augmentation groups, with the augmentation group overall demonstrating better outcomes. ${ }^{36}$ Harris et al. ${ }^{34}$ published minimal clinically important difference and PASS scores for commonly used patient report outcome scores and showed that for IKDC, minimal clinically important difference was 16.7, whereas PASS was 75.9. Patients in both groups surpassed both of these thresholds because the change from preoperative to postoperative IKDC scores were 39.1 and 30.6 for the augmentation and nonaugmentation groups, respectively; the average postoperative scores for each group was 79.4 and 77.4, respectively.

In a systematic review of pediatric and adult patients undergoing MPFL reconstruction, Manjunath et al. ${ }^{37}$ found that the overall return to play rate was $85.1 \%$, with $68.3 \%$ returning to the same level of play. Sport participation was lower overall in the current study population. Patients who underwent MPFL reconstruction participate in sport at similar levels, regardless of technique used $(20 \%$ nonaugmentation vs $31 \%$ augmentation, $P=.516$ ). Interestingly, patients in the nonaugmentation group tended to avoid sport less than their counterparts who underwent augmentation $(30 \%$ vs $41 \%$ ), although this difference was not significant $(P=0.417)$. Although IKDC scores and ratings of percent of normal of the knee trended higher for the tape augmentation group, the rates of sport participation trended paradoxically lower.

Manjunath et al. ${ }^{37}$ found that the rate of recurrent instability events following MPFL reconstruction in a combined pediatric and adult population was $5.4 \%$. Lind et al. ${ }^{38}$ found that $20 \%$ of pediatric patients experienced re-dislocation, compared with $5 \%$ in the adult population. The current study found that 2 knees $(6 \%)$ in the augmentation group developed recurrent subjective instability or dislocation after initial surgery requiring surgical correction, compared to 4 knees $(17 \%)$ knees in the nonaugmentation group $(P=.181)$, with an overall rate of $11 \%(6 / 56)$. Pediatric patients appear more prone to recurrent instability and dislocation after MPFL reconstruction than their adult counterparts. $^{38}$ The data from the current study show that tape augmentation might play a role in improving outcomes in skeletally mature adolescent patients with regard to recurrent instability rates after MPFL reconstruction.

In their comparison between patients who underwent MPFL reconstruction with and without polyester suture augmentation, Xie et al. $^{36}$ found that no patients in the augmentation group experienced redislocation, compared with 2 patients $(4.7 \%)$ in the nonaugmentation group, and that failure occurred in 1 patient $(2.4 \%)$ in the augmentation group versus 10 patients $(23.3 \%)$ in the nonaugmentation group. The findings of the current study align with those of Xie et al. $^{36}$ Two of 34 knees $(5.8 \%)$ underwent revision MPFL reconstruction in the augmentation group, compared with 4 of 24 knees $(16.7 \%)$ in the nonaugmentation group. However, the present study differs from that of Xie et al. ${ }^{36}$ in that there was a statistically significant increase in the number of injuries sustained to the ipsilateral knee between the nonaugmentation group $(29.2 \%)$ and the augmentation group $(6.3 \%)$. Notably, procedures in the present study did not use a standard graft type; gracilis, semitendinosis, tibialis anterior, and peroneus longus allograft were used. However, Stupay et al. ${ }^{39}$ demonstrated in their systematic review of 34 articles that graft choice, excluding tape augmentation, did not impact outcomes or complications of MPFL reconstruction, supporting that the observed difference in the present study is likely attributable to tape augmentation.

Graft deterioration may contribute to subsequent ipsilateral injuries in the nonaugmented group. Zhao et al. ${ }^{40}$ demonstrated that correction of static patellar position deteriorated over a 5-year follow-up after MPFL reconstruction without polyester suture augmentation. Xie et al. ${ }^{36}$ hypothesized that shortly after harvest, the tendon loses blood supply and suffers necrosis, such that the initial tendon strength observed deteriorates over time. Further cadaveric biomechanical study may better elucidate the relationship between graft age and failure load with and without tape augmentation.

\section{Limitations}

There are several limitations in this study. First, the response rate was $61 \%$. This loss to follow-up leads to attrition bias, which may affect the validity of the conclusions. A larger sample size may have demonstrated more significant differences between the 2 groups. Multiple attempts were made to contact study patients over a several-month period. Second, procedures in the present study did not use a standard graft type; gracilis, semitendinosis, tibialis anterior, and peroneus longus allograft were used. Third, follow-up time differed significantly between the 2 groups. Patients in the augmentation group had shorter follow-up because of tape augmentation not having been incorporated into the primary surgeon's (S.K.A.) practice until more recently. Fourth, lack of availability of preoperative radiographs limits potential elucidation of morphologic differences that may affect patellar stability, including trochlear dysplasia, between the two groups. Fifth, this study is inherently limited through its design as a retrospective study. Finally, all patients underwent 
surgery at a single institution by a single surgeon (S.K.A.), which may limit generalizability of these findings, although use of a single surgeon minimizes discrepancies in surgical technique.

\section{Conclusion}

There were no significant differences in patientreported outcomes after MPFL reconstruction with or without tape augmentation. Tape augmentation significantly decreased the risk of subsequent ipsilateral knee injuries, although did not show a significant difference in recurrent dislocations.

\section{References}

1. Aglietti P, Buzzi R, Insall J. Disorders of the patellofemoral joint In: Surgery of the knee. 3rd ed. London: Churchill Livingstone, 2001;913-1042.

2. Atkin DM, Fithian DC, Marangi KS, Stone ML, Dobson BE, Mendelsohn C. Characteristics of patients with primary acute lateral patellar dislocation and their recovery within the first 6 months of injury. Am J Sports Med 2000;28:472-479.

3. Nietosvaara Y, Aalto K, Kallio PE. Acute patellar dislocation in children: Incidence and associated osteochondral fractures. J Pediatr Orthop 1994;14:513-515.

4. Apostolovic M, Vukomanovic B, Slavkovic N, et al. Acute patellar dislocation in adolescents: Operative versus nonoperative treatment. Int Orthop 2011;35:1483-1487.

5. Stefancin JJ, Parker RD. First-time traumatic patellar dislocation: A systematic review. Clin Orthop Relat Res 2007;455:93-101.

6. Camanho GL, Viegas A de C, Bitar AC, Demange MK, Hernandez AJ. Conservative versus surgical treatment for repair of the medial patellofemoral ligament in acute dislocations of the patella. Arthroscopy 2009;25:620-625.

7. Mäenpää H, Huhtala $H$, Lehto MU. Recurrence after patellar dislocation. Redislocation in 37/75 patients followed for 6-24 years. Acta Orthop Scand 1997;68:424-426.

8. Mäenpää H, Lehto MU. Patellar dislocation. The longterm results of nonoperative management in 100 patients. Am J Sports Med 1997;25:213-217.

9. Palmu S, Kallio PE, Donell ST, Helenius I, Nietosvaara Y. Acute patellar dislocation in children and adolescents: A randomized clinical trial. J Bone Joint Surg Am 2008;90: 463-470.

10. Smith TO, Song F, Donell ST, Hing CB. Operative versus non-operative management of patellar dislocation. A meta-analysis. Knee Surg Sports Traumatol Arthrosc $2011 ; 19: 988-998$.

11. Arendt EA, Fithian DC, Cohen E. Current concepts of lateral patella dislocation. Clin Sports Med 2002;21: 499-519.

12. Cofield RH, Bryan RS. Acute dislocation of the patella: Results of conservative treatment. J Trauma 1977;17: 526-531.

13. Macnab I. Recurrent dislocation of the patella. J Bone Joint Surg Am 1952;34 A(4):957-967. passim.
14. Hawkins RJ, Bell RH, Anisette G. Acute patellar dislocations. The natural history. Am J Sports Med 1986;14: 117-120.

15. Lewallen LW, McIntosh AL, Dahm DL. Predictors of recurrent instability after acute patellofemoral dislocation in pediatric and adolescent patients. Am J Sports Med 2013:41:575-581.

16. Lewallen L, McIntosh A, Dahm D. First-time patellofemoral dislocation: Risk factors for recurrent instability. J Knee Surg 2015;28:303-309.

17. Reider B, Marshall JL, Warren RF. Clinical characteristics of patellar disorders in young athletes. Am J Sports Med 1981;9:270-274.

18. Insall J, Goldberg V, Salvati E. Recurrent dislocation and the high-riding patella. Clin Orthop Relat Res 1972;88:67-69.

19. Neyret P, Robinson AH, Le Coultre B, Lapra C, Chambat P. Patellar tendon length-The factor in patellar instability? Knee 2002;9:3-6.

20. Simmons JE, Cameron JC. Patella alta and recurrent dislocation of the patella. Clin Orthop Relat Res 1992;(274): 265-269.

21. Dejour H, Walch G, Nove-Josserand L, Guier C. Factors of patellar instability: an anatomic radiographic study. Knee Surg Sports Traumatol Arthrosc 1994;2:19-26.

22. Dejour H, Walch G, Neyret P, Adeleine P. La dysplasie de la trochlée fémorale. Rev Chir Orthop Reparatrice Appar Mot 1990;76(1):45-54 [in French].

23. Crosby EB, Insall J. Recurrent dislocation of the patella. Relation of treatment to osteoarthritis. J Bone Joint Surg Am 1976;58:9-13.

24. Mäenpää H, Lehto MU. Patellofemoral osteoarthritis after patellar dislocation. Clin Orthop Relat Res 1997;339: 156-162.

25. Vellios EE, Trivellas M, Arshi A, Beck JJ. Recurrent patellofemoral instability in the pediatric patient: Management and pitfalls. Curr Rev Musculoskelet Med 2020;13: 58-68.

26. Hopper GP, Heusdens CHW, Dossche L, Mackay GM. Medial patellofemoral ligament repair with suture tape augmentation. Arthrosc Tech 2018;8(1):el-e5.

27. Ishibashi Y, Kimura Y, Sasaki E, Sasaki S, Yamamoto Y, Tsuda E. Medial patellofemoral ligament reconstruction using FiberTape and knotless SwiveLock anchors. Arthrosc Tech 2020;9(8):el 197-el202.

28. Schottle PB, Romero J, Schmeling A, Weiler A. Technical note: Anatomical reconstruction of the medial patellofemoral ligament using a free gracilis autograft. Arch Orthop Trauma Surg 2008;128:479-484.

29. Irrgang JJ, Anderson AF, Boland AL, et al. Development and validation of the international knee documentation committee subjective knee form. Am J Sports Med 2001;29: 600-613.

30. Irrgang JJ, Anderson AF, Boland AL, et al. Responsiveness of the International Knee Documentation Committee Subjective Knee Form. Am J Sports Med 2006;34: 1567-1573.

31. Anderson AF, Irrgang JJ, Kocher MS, Mann BJ, Harrast JJ, International Knee Documentation Committee. The International Knee Documentation Committee Subjective Knee Evaluation Form: normative data. Am J Sports Med 2006;34:128-135. 
32. Greco NJ, Anderson AF, Mann BJ, et al. Responsiveness of the International Knee Documentation Committee Subjective Knee Form in comparison to the Western Ontario and McMaster Universities Osteoarthritis Index, modified Cincinnati Knee Rating System, and Short Form 36 in patients with focal articular cartilage defects. Am J Sports Med 2010;38:891-902.

33. Shirazi CP, Israel HA, Kaar SG. Is the Marx activity scale reliable in patients younger than 18 years? Sports Health 2016;8:145-148.

34. Harris JD, Brand JC, Cote MP, Faucett SC, Dhawan A. Research pearls: The significance of statistics and perils of pooling. Part 1: Clinical versus statistical significance. Arthroscopy 2017;33:1102-1112.

35. Muller B, Yabroudi MA, Lynch A, et al. Defining thresholds for the patient acceptable symptom state for the IKDC Subjective Knee Form and KOOS for patients who underwent ACL reconstruction. Am J Sports Med 2016;44: 2820-2826.

36. Xie G, Zhao J, Huangfu X, He Y. Medial patellofemoral ligament reconstruction using semitendinosus tendons:
Polyester suture augmentation versus nonaugmentation. Am J Sports Med 2012;40:1365-1374.

37. Manjunath AK, Hurley ET, Jazrawi LM, Strauss EJ. Return to play after medial patellofemoral ligament reconstruction: A systematic review. Am J Sports Med 2021;49: 1094- 1100.

38. Lind M, Enderlein D, Nielsen T, Christiansen SE, Faunø P. Clinical outcome after reconstruction of the medial patellofemoral ligament in paediatric patients with recurrent patella instability. Knee Surg Sports Traumatol Arthrosc 2016;24:666-671.

39. Stupay KL, Swart E, Shubin Stein BE. Widespread implementation of medial patellofemoral ligament reconstruction for recurrent patellar instability maintains functional outcomes at midterm to long-term follow-up while decreasing complication rates: A systematic review. Arthroscopy 2015;31:1372-1380.

40. Zhao J, Huangfu X, He Y. The role of medial retinaculum plication versus medial patellofemoral ligament reconstruction in combined procedures for recurrent patellar instability in adults. Am J Sports Med 2012;40:1355-1364. 
Appendix 1. Patient Survey

\begin{tabular}{|c|c|}
\hline \multicolumn{2}{|l|}{ Demographics } \\
\hline \multicolumn{2}{|l|}{ What is your name? } \\
\hline $\begin{array}{l}\text { Are you filling this questionnaire } \\
\text { out for yourself or your child? }\end{array}$ & $\begin{array}{ll} & \text { My self } \\
\bigcirc & \text { My child }\end{array}$ \\
\hline $\begin{array}{l}\text { Was surgery performed on the } \\
\text { affected knee? }\end{array}$ & $\begin{array}{ll}\bigcirc & \text { Yes } \\
\bigcirc & \text { No }\end{array}$ \\
\hline $\begin{array}{l}\text { On which knee did Dr. XXX or Dr. } \\
\text { XXX perform surgery?*}\end{array}$ & $\begin{array}{ll} & \text { Left } \\
\bigcirc & \text { Right } \\
0 & \text { Both }\end{array}$ \\
\hline \multicolumn{2}{|c|}{2000 IKDC Subjective Knee Evaluation Form } \\
\hline $\begin{array}{l}\text { What is the highest level of activity } \\
\text { that you can perform without } \\
\text { significant knee pain? }\end{array}$ & $\begin{array}{l}\text { Very strenuous activities like jumping or pivoting } \\
\text { as in basketball or soccer } \\
\text { Strenuous activities like heavy physical work, } \\
\text { skiing or tennis } \\
\text { Moderate activities like moderate physical work, } \\
\text { running or jogging } \\
\text { Light activities like walking, housework or } \\
\text { yardwork } \\
\text { Unable to perform any of the above activities due to } \\
\text { knee pain }\end{array}$ \\
\hline $\begin{array}{l}\text { During the past } 4 \text { weeks, or since } \\
\text { your injury, how often have you had } \\
\text { pain? }(0=\text { Never and } 10=\text { Constant })\end{array}$ & 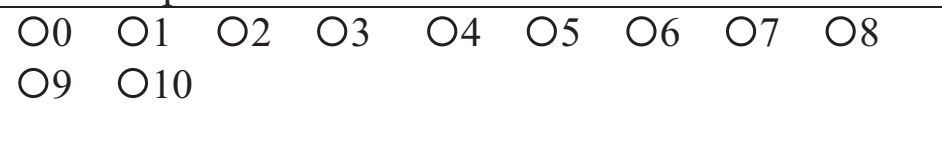 \\
\hline $\begin{array}{l}\text { If you have pain, how severe is it? } \\
(0=\text { No pain and } 10=\text { worst pain } \\
\text { imaginable })\end{array}$ & $\begin{array}{lllllllll}O 0 & \text { O1 } & \text { O2 } & \text { O3 } & \text { O4 } & \text { O5 } & \text { O6 } & \text { O7 } & \text { O8 } \\
\text { O9 } & \text { O10 } & & & & & & & \end{array}$ \\
\hline $\begin{array}{l}\text { During the past } 4 \text { weeks, or since } \\
\text { your injury, how stiff or swollen } \\
\text { was your knee? }\end{array}$ & $\begin{array}{ll}O & \text { Not at all } \\
\bigcirc & \text { Mildly } \\
\bigcirc & \text { Moderately } \\
\bigcirc & \text { Very } \\
\bigcirc & \text { Extremely } \\
\end{array}$ \\
\hline $\begin{array}{l}\text { What is the highest level of activity } \\
\text { you can perform without significant } \\
\text { swelling in your knee? }\end{array}$ & $\begin{array}{l}\text { Very strenuous activities like jumping or pivoting } \\
\text { as in basketball or soccer } \\
\text { Strenuous activities like heavy physical work, } \\
\text { skiing or tennis } \\
\text { Moderate activities like moderate physical work, } \\
\text { running or jogging } \\
\text { Light activities like walking, housework or } \\
\text { yardwork } \\
\text { Unable to perform any of the above activities due to } \\
\text { knee pain }\end{array}$ \\
\hline $\begin{array}{l}\text { During the past } 4 \text { weeks, or since } \\
\text { your injury, did your knee lock or } \\
\text { catch? }\end{array}$ & $\begin{array}{ll}\mathrm{O} & \mathrm{Yes} \\
\mathrm{O} & \mathrm{No}\end{array}$ \\
\hline
\end{tabular}




\begin{tabular}{|c|c|c|c|c|c|}
\hline $\begin{array}{l}\text { What is the highest level of activity } \\
\text { you can perform without significant } \\
\text { giving way in your knee? }\end{array}$ & \multicolumn{5}{|c|}{$\begin{array}{l}\text { Very strenuous activities like jumping or pivoting } \\
\text { as in basketball or soccer } \\
\text { Strenuous activities like heavy physical work, } \\
\text { skiing or tennis } \\
\text { Moderate activities like moderate physical work, } \\
\text { running or jogging } \\
\text { Light activities like walking, housework or } \\
\text { yardwork } \\
\text { Unable to perform any of the above activities due to } \\
\text { knee pain }\end{array}$} \\
\hline $\begin{array}{l}\text { What is the highest level of activity } \\
\text { you can participate in on a regular } \\
\text { basis? }\end{array}$ & \multicolumn{5}{|c|}{$\begin{array}{l}\text { Very strenuous activities like jumping or pivoting } \\
\text { as in basketball or soccer } \\
\text { Strenuous activities like heavy physical work, } \\
\text { skiing or tennis } \\
\text { Moderate activities like moderate physical work, } \\
\text { running or jogging } \\
\text { Light activities like walking, housework or } \\
\text { yardwork } \\
\text { Unable to perform any of the above activities due to } \\
\text { knee pain }\end{array}$} \\
\hline $\begin{array}{l}\text { How does your knee affect your } \\
\text { ability to: }\end{array}$ & $\begin{array}{l}\text { Not } \\
\text { difficult } \\
\text { at all }\end{array}$ & $\begin{array}{l}\text { Minimally } \\
\text { difficult }\end{array}$ & $\begin{array}{l}\text { Moderately } \\
\text { difficult }\end{array}$ & $\begin{array}{c}\text { Extremely } \\
\text { difficult }\end{array}$ & $\begin{array}{c}\text { Unable } \\
\text { to }\end{array}$ \\
\hline a. Go up stairs & $\mathrm{O}$ & $\mathrm{O}$ & $\mathrm{O}$ & $\mathrm{O}$ & $\mathrm{O}$ \\
\hline b. Go down stairs & $\mathrm{O}$ & $\mathrm{O}$ & $\mathrm{O}$ & $\mathrm{O}$ & $\mathrm{O}$ \\
\hline $\begin{array}{l}\text { c. Kneel on the front of your } \\
\text { knee }\end{array}$ & O & $\mathrm{O}$ & O & $\mathrm{O}$ & $\mathrm{O}$ \\
\hline d. Squat & $\mathrm{O}$ & $\mathrm{O}$ & $\mathrm{O}$ & $\mathrm{O}$ & $\mathrm{O}$ \\
\hline e. Sit with your knee bent & $\mathrm{O}$ & O & O & O & $\mathrm{O}$ \\
\hline f. Rise from a chair & $\mathrm{O}$ & $\mathrm{O}$ & $\mathrm{O}$ & $\mathrm{O}$ & $\mathrm{O}$ \\
\hline g. Run straight ahead & $\mathrm{O}$ & $\mathrm{O}$ & $\mathrm{O}$ & $\mathrm{O}$ & $\mathrm{O}$ \\
\hline $\begin{array}{l}\text { h. Jump and land on your } \\
\text { involved leg }\end{array}$ & $\mathrm{O}$ & $\mathrm{O}$ & $\mathrm{O}$ & $\mathrm{O}$ & $\mathrm{O}$ \\
\hline i. Stop and start quickly & $\mathrm{O}$ & $\mathrm{O}$ & $\mathrm{O}$ & O & $\mathrm{O}$ \\
\hline \multicolumn{6}{|c|}{$\begin{array}{l}\text { Function: How would you rate the function of your knee on a scale of } 0 \text { to } 10 \text { with } 10 \text { being } \\
\text { normal, excellent function and } 0 \text { being the inability to perform any of your usual daily } \\
\text { activities which may include sports? }\end{array}$} \\
\hline $\begin{array}{l}\text { Function prior to your knee injury: } \\
(0=\text { Cannot perform daily activities } \\
\text { and } 10=\text { No limitation in daily } \\
\text { activities })\end{array}$ & $\begin{array}{ll}\bigcirc 0 & \bigcirc \\
\text { O9 } & \bigcirc\end{array}$ & $1002 \quad \bigcirc 3$ & O4 O5 & O6 & \\
\hline
\end{tabular}




\begin{tabular}{|c|c|}
\hline $\begin{array}{l}\text { Current function of your knee: }(0= \\
\text { Cannot perform daily activities and } \\
10=\text { No limitation in daily } \\
\text { activities })\end{array}$ & 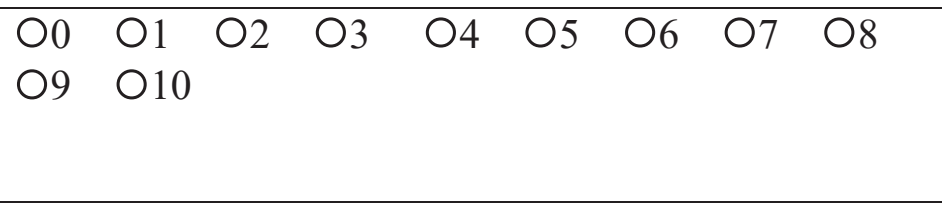 \\
\hline \multicolumn{2}{|l|}{ Marx Activity Scale } \\
\hline \multicolumn{2}{|c|}{$\begin{array}{l}\text { Please indicate how often you performed each activity in your healthiest and most active state, } \\
\text { in the past year. }\end{array}$} \\
\hline $\begin{array}{l}\text { Running: running while playing a } \\
\text { sport or jogging }\end{array}$ & $\begin{array}{l}\text { Less than one time in a month } \\
\text { One time in a month } \\
\text { One time in a week } \\
2 \text { or } 3 \text { times in a week } \\
04 \text { or more times in a week }\end{array}$ \\
\hline $\begin{array}{l}\text { Cutting: changes directions while } \\
\text { running }\end{array}$ & $\begin{array}{l}\text { Less than one time in a month } \\
\text { One time in a month } \\
\text { One time in a week } \\
\text { 2 or } 3 \text { times in a week } \\
4 \text { or more times in a week }\end{array}$ \\
\hline $\begin{array}{l}\text { Decelerating: coming to a quick } \\
\text { stop while running }\end{array}$ & $\begin{array}{l}\text { Less than one time in a month } \\
\text { One time in a month } \\
\text { One time in a week } \\
2 \text { or } 3 \text { times in a week } \\
4 \text { or more times in a week }\end{array}$ \\
\hline $\begin{array}{l}\text { Pivoting: turning your body with } \\
\text { your foot planted while playing a } \\
\text { sport; For example: skiing, skating, } \\
\text { kicking, throwing, hitting a ball } \\
\text { (golf, tennis, squash), etc. }\end{array}$ & $\begin{array}{l}\text { Less than one time in a month } \\
0 \text { One time in a month } \\
\text { One time in a week } \\
\bigcirc 2 \text { or } 3 \text { times in a week } \\
\text { 4 or more times in a week }\end{array}$ \\
\hline \multicolumn{2}{|l|}{ Survey } \\
\hline $\begin{array}{l}\text { How would you rate your affected } \\
\text { knee today as a percentage of } \\
\text { normal ( } 0-100 \% \text { scale with } 100 \% \\
\text { being "normal")? }\end{array}$ & $0 \% \quad 50 \%$ \\
\hline $\begin{array}{l}\text { Please indicate how often you } \\
\text { experienced knee instability events } \\
\text { (i.e., the feeling of your knee giving } \\
\text { way), in the past year? }\end{array}$ & $\begin{array}{l}\text { Less than one time in a month } \\
\text { One time in a month } \\
\text { One time in a week } \\
2 \text { or } 3 \text { times in a week } \\
04 \text { or more times in a week }\end{array}$ \\
\hline $\begin{array}{l}\text { How satisfied are you with the } \\
\text { results of your surgery? }\end{array}$ & $\begin{array}{ll}O & \text { Very Satisfied } \\
O & \text { Satisfied } \\
O & \text { Neutral } \\
\bigcirc & \text { Unsatisfied } \\
O & \text { Very Unsatisfied } \\
\end{array}$ \\
\hline $\begin{array}{l}\text { Looking back, if you "had to do it } \\
\text { all over again", would you have the }\end{array}$ & $\begin{array}{ll}\text { Definitely, yes } \\
\text { Probably, yes }\end{array}$ \\
\hline
\end{tabular}




\begin{tabular}{|c|c|}
\hline surgery again? & $\begin{array}{ll} & \text { Unsure } \\
\text { O } & \text { Probably, no } \\
\text { O } & \text { Definitely, no }\end{array}$ \\
\hline $\begin{array}{l}\text { Have you had any further surgeries } \\
\text { on your knee since your initial knee } \\
\text { surgery with Dr. XXX or Dr. } \\
\text { XXX? } *^{\dagger}\end{array}$ & $\begin{array}{lll} & \text { Yes } \\
\text { O No }\end{array}$ \\
\hline $\begin{array}{l}\text { Please explain what further } \\
\text { surgeries you've had since your } \\
\text { initial knee surgery with Dr. XXX } \\
\text { or Dr. XXX.* Include approximate } \\
\text { date of surgery, if known. }\end{array}$ & \\
\hline $\begin{array}{l}\text { Since your knee surgery, have you } \\
\text { experienced any other injuries to } \\
\text { your surgical knee? }\end{array}$ & $\begin{array}{ll}O & \text { Yes } \\
\bigcirc & \text { No }\end{array}$ \\
\hline $\begin{array}{l}\text { Since your knee surgeries, have you } \\
\text { experienced any injuries to your } \\
\text { other knee? }\end{array}$ & $\begin{array}{ll}\text { Y } & \text { Yes } \\
\text { O } & \text { No }\end{array}$ \\
\hline Do you currently play any sports? & $\begin{array}{ll} & \text { Yes } \\
\text { O No }\end{array}$ \\
\hline $\begin{array}{l}\text { What sports do you currently play } \\
\text { and at what level (competitive, } \\
\text { recreational, etc)? }\end{array}$ & (Example: recreational basketball, competitive soccer) \\
\hline $\begin{array}{l}\text { Are there any sports you would like } \\
\text { to play but avoid because of your } \\
\text { knee? }\end{array}$ & $\begin{array}{ll} & \text { Yes } \\
\text { O No }\end{array}$ \\
\hline Why do you avoid the activity? & $\begin{array}{l}\square \text { Personal choice } \\
\square \text { Outside influence (parent, friend, coach, therapist, } \\
\text { physician, etc.) } \\
\square \text { Knee does not tolerate sport } \\
\square \text { Other (specify below) }\end{array}$ \\
\hline $\begin{array}{l}\text { Do you notice any stiffness or loss } \\
\text { of motion in your knee? }\end{array}$ & $\begin{array}{l}O \text { Yes } \\
\text { O No }\end{array}$ \\
\hline $\begin{array}{l}\text { How would you rate your pain on a } \\
\text { scale of } 0-10 \text { at rest? }(0=\text { No pain } \\
\text { and } 10=\text { worst pain imaginable })\end{array}$ & $\begin{array}{lllllllll}\text { O0 } & \text { O1 } & \text { O2 } & \text { O3 } & \text { O4 } & \text { O5 } & \text { O6 } & \text { O7 } & \text { O8 } \\
\text { O9 } & \text { O10 } & & & & & & & \\
\end{array}$ \\
\hline $\begin{array}{l}\text { How would you rate your pain on a } \\
\text { scale of } 0-10 \text { during daily activities? } \\
(0=\text { No pain and } 10=\text { worst pain } \\
\text { imaginable })\end{array}$ & $\begin{array}{lllllllll}\text { O0 } & \text { O1 } & \text { O2 } & \text { O3 } & \text { O4 } & \text { O5 } & \text { O6 } & \text { O7 } & \text { O8 } \\
\text { O9 } & \text { O10 } & & & & & & & \end{array}$ \\
\hline $\begin{array}{l}\text { How would you rate your pain on a } \\
\text { scale of } 0-10 \text { during sport activities? } \\
(0=\text { No pain and } 10=\text { worst pain } \\
\text { imaginable })\end{array}$ & $\begin{array}{lllllllll}\text { O0 } & \text { O1 } & \text { O2 } & \text { O3 } & \text { O4 } & \text { O5 } & \text { O6 } & \text { O7 } & \text { O8 } \\
\text { O9 } & \text { O10 } & & & & & & & \end{array}$ \\
\hline \multicolumn{2}{|c|}{$\begin{array}{l}\text { *This survey was utilized for several studies. Only patients of a single surgeon (SKA) who } \\
\text { met inclusion and exclusion criteria were considered in the present study. }\end{array}$} \\
\hline${ }^{\dagger}$ If affirmative, col & \\
\hline
\end{tabular}

